\title{
Outcomes of chronic dialysis in Korean children with respect to survival rates and causes of death
}

Hye Jin Chang, MD', Kyoung Hee Han, MD², Min Hyun Cho, MD², Young Seo Park, MD, Hee Gyung Kang, MD', Hae II Cheong, $M D^{1,5}$, II Soo Ha, MD, PhD ${ }^{1,5}$

${ }^{1}$ Department of Pediatrics, Seoul National University Children's Hospital, Seoul, ${ }^{2}$ Department of Pediatrics, Jeju National University Hospital, Jeju, ${ }^{3}$ Department of Pediatrics, Kyungpook National University School of Medicine, Daegu, ${ }^{4}$ Department of Pediatrics, Asan Medical Center, University of Ulsan College of Medicine, Seoul, ${ }^{5}$ Kidney Research Institute, Medical Research Center, Seoul National University College of Medicine, Seoul, Korea

Purpose: Adult Korean patients on chronic dialysis have a 9-year survival rate of $50 \%$, with cardiovascular problems being the most significant cause of death. The 2011 annual report of the North American Pediatric Renal Trials and Collaborative Studies group reported 3-year survival rates of 93.4\% and relatively poorer survival in younger patients.

Methods: In this study, we have reviewed data from Korean Pediatric Chronic Kidney Disease Registry from 2002 to 2010 to assess survival rates and causes of death in Korean children on chronic dialysis. Results: The overall estimated patient survival rates were $98.4 \%, 94.4 \%$, and $92.1 \%$ at 1,3 , and 5 years, respectively. No significant difference was observed in survival rates between patients on peritoneal dialysis and those on hemodialysis. Patients for whom dialysis was initiated before 2 years of age $(n=40)$ had significantly lower survival rates than those for whom dialysis was initiated at $6-11$ years of age $(n=140)$. In all, 26 patients had died; the mortality rate was 19.9 per 1,000 patient years. The most common causes of death were infections and comorbidities such as malignancy and central nervous system (CNS) or liver diseases.

Conclusion: The outcomes observed in this study were better than those observed in adults and comparable to those observed in pediatric studies in other countries. To improve the outcomes of children on chronic dialysis, it is necessary to prevent dialysis-related complications such as infection, congestive heart failure, or CNS hemorrhage and best control treatable comorbidities.

Key words: Survival, Outcomes, End-stage renal disease, Dialysis, Child

\section{Introduction}

End-stage renal disease (ESRD), the terminal stage of chronic kidney disease (CKD), is a growing health problem worldwide. According to the United States Renal Data System (USRDS), the annual incidence of ESRD increased from 13 per million of the age-related population (MARP) in the 1988 to 15 per MARP in the $2003^{11}$. European Dialysis and Transplant Association (EDTA) registry from 3,184 patients less than the age of 20 years showed that the incidence of ESRD rose from 7.1 per MARP in the 1980-1984 to 9.9 per MARP over the next 15 years, and the prevalence of patients on renal replacement therapy (RRT) increased from 22.9 per MARP in 1980 to 62.1 per MARP in $2000^{2)}$. In Korean children, according to the data from the Korean Health Insurance Review \& Assessment Service in 2009, 435 children were on RRT, and the incidence and the prevalence of ESRD were 10.5 and 38.5 per MARP respectively (unpublished data). In these data, 52\% of patients (141/271) on chronic dialysis were registered in the Korean Pediatric CKD (KPCKD) Registry.
Corresponding author: II Soo Ha, MD, PhD Department of Pediatrics, Seoul National University Children's Hospital, 101 Daehak-ro, Jongno-gu, Seoul 110-744, Korea

Tel: +82-2-2072-2858

Fax: +82-2-743-3455

E-mail: ilsooha@snu.ac.kr

Received: 11 September, 2012

Revised: 29 September, 2012

Accepted: 10 October, 2012
Copyright (C) 2014 by The Korean Pediatric Society

This is an open-access article distributed under the terms of the Creative Commons Attribution NonCommercial License (http://creativecommons.org/ licenses/by-nc/3.0/) which permits unrestricted noncommercial use, distribution, and reproduction in any medium, provided the original work is properly cited. 
Although the expected outcome of ESRD has improved substantially over the past 40 years, the overall 10-year survival remains approximately $80 \%$, and the mortality rate (MR) is still 30-150 times higher than that of children without ESRD ${ }^{3)}$. The 2011 annual report of the North American Pediatric Renal Trials and Collaborative Studies (NAPRTCS) group reported 3-year survival rates of $93.4 \%$ and relatively poorer survival in younger patients ${ }^{4}$. Cardiopulmonary problems and infection were the major causes of death. In Korea, data on the outcomes of children on chronic dialysis have not been sufficiently reported. Adult Korean patients on chronic dialysis were reported by the Committee of the Korean Society of Nephrology in 2009 to have a 5-year survival rate of approximately $65 \%$ and a 9 -year survival rate of $50 \%$. The most common cause of death was cardiovascular problems ${ }^{5}$.

In this study, we reviewed the KPCKD registry data to assess the outcomes of Korean children on chronic dialysis.

\section{Materials and methods}

\section{Study population}

Data from the KPCKD registry were reviewed for the period from January 2002 to December 2010. This web-based registry (http://pedcrf.or.kr), launched in 2004 by the Korean Board of Collaboration for Pediatric CKD, has collected clinical data for patients with CKD. Patients who had initiated either peritoneal dialysis (PD) or hemodialysis (HD) before the age of 20 years were selected for this study. The follow-up duration was defined as the period from the initiation of dialysis to the date of renal transplantation, death, the date of transfer to internist or the last data entry. To analyze the difference in outcome by the patient's age at the initiation of dialysis, the study population was divided into four subgroups: <2 years, 2-5 years, 6-11 years, and $\geq 12$ years of age at the initiation of dialysis.

\section{Data collection}

Patient survival data from the registry were reviewed, and for deceased patients, additional data were collected from the patient's medical records, including the age of death, the modality of RRT, the total duration of RRT and the cause of death. When multiple causes of death were identified, the most direct or the most significant causative factor was designated as the cause of death.

\section{Statistics}

Patient survival rates were calculated by the Kaplan-Meier method using PASW ver. 18.0 (SPSS Inc., Chicago, IL, USA) as the cumulative survival probability at the 1st, 3rd, 5th year of chronic dialysis and were described as 1-, 3- and 5-year survival. To evaluate differences in the modality of dialysis (HD or PD),
Pearson chi-square test or Fisher exact test was used. The MR was calculated by dividing the number of deaths by the total patient follow-up time (i.e., the sum of the duration of chronic dialysis for all patients) in years and multiplying by 1,000 , which shows the number of deaths per 1,000 patient years. $P$ values less than 0.05 were considered to be statistically significant.

\section{Results}

\section{Korean pediatric patients with ESRD}

Three hundred seventy-eight patients had initiated chronic dialysis before their age of 20 years at the time of data collection (January 10th, 2011). Their median age at the initiation of chronic dialysis was 9.7 years (range, 0-19.7 years), and the median duration of chronic dialysis was 41.0 months (range, 3.0-240.0 months). The number of patients on PD was 304 and that of patients on $\mathrm{HD}$ was 74.

\section{Survival of ESRD patients}

The overall patient survival rate was $98.4 \%$ at 1 year, 94.4\% at 3 years, and $92.1 \%$ at 5 years (Fig. 1A). The overall 1-, 3-, and 5-year survival rate for PD patients was 98.3\%, 94.3\%, and 92.3\%, and that for HD patients was 98.6\%, 94.6\%, and 91.1\%, respectively (Fig. 1B). There was no significant difference of survival between the patients on PD and those on $\mathrm{HD}(P=0.908)$. The 5-year survival of patients who initiated dialysis at an age less than 2 years $(n=40)$ was $70.6 \%$, at 2 to 5 years $(n=52)$ was $91.1 \%$, at 6 to 11 years $(n=140)$ was $94.4 \%$, and at or over 12 years $(n=146)$ was $96.5 \%$ (Fig. 1C). The 5-year survival of children less than 2 years of age was significantly lower than those of other age groups (0-1 year vs. $2-5$ years, $P=0.115$; $0-1$ year vs. $6-11$ years, $P=0.001 ; 0-1$ year vs. $\geq 12$ years, $P=0.001$ ). The $1-, 3-$, and 5-year survival rate for patients who started dialysis earlier than 2 years of age were 92.5\%, 82.0\%, and 70.6\%, respectively.

\section{Mortality}

During the period from 2002 to 2010, a total of 26 patients (male:female, 15:11) died while on chronic dialysis (HD:PD, 8:18), at a median age of 9.3 years (range, 0.3-25.7 years). The MR of this study was 19.9 per 1,000 patient years. The median age at the initiation of RRT was 7.3 years, and the median duration from the initiation of dialysis to death was 35.4 months.

\section{Causes of death}

The most common cause of death was infection $(n=6) ; 5$ from sepsis, 1 from pneumonia. of 6 patients, 3 patients were on HD. Five patients died due to the progression of an underlying malignancy (brain tumor, neuroblastoma, rhabdomyosarcoma, 


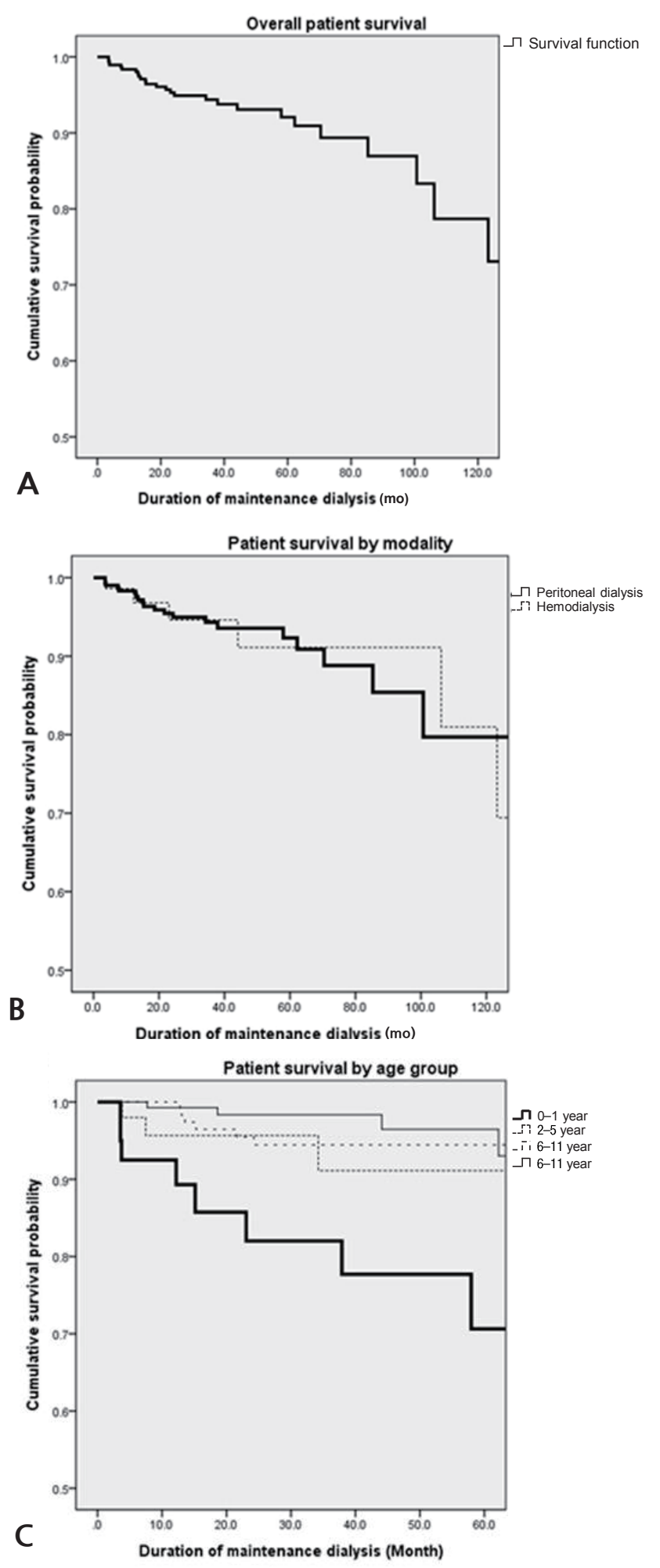

Fig. 1. Survival rate of Korean children on chronic dialysis. (A) Cumulative survival rate of all the patients; (B) cumulative survival rates of patients on different types of dialysis; $(C)$ cumulative survival rates of patients in whom dialysis was initiated at different age groups.
Table 1. Causes of death of Korean children on chronic dialysis

\begin{tabular}{lllll}
\hline Causes of death & Total & PD & HD & $P$-value \\
\hline Infection & $6(23.1)$ & $3(15.0)$ & $3(50.0)$ & 0.112 \\
Malignancy & $5(19.2)$ & $4(20.0)$ & $1(16.7)$ & 1.000 \\
Cardiopulmonary & $2(7.7)$ & $1(5.0)$ & $1(16.7)$ & 1.000 \\
Liver disease & $2(7.7)$ & $1(5.0)$ & $1(16.7)$ & 0.415 \\
Neurologic disease & $2(7.7)$ & $2(10.0)$ & $0(0)$ & 1.000 \\
CNS hemorrhage & $2(7.7)$ & $2(10.0)$ & $0(0)$ & 1.000 \\
Others & $2(7.7)$ & $2(10.0)$ & $0(0)$ & 0.415 \\
Unknown & $5(19.2)$ & $5(25.0)$ & $0(0)$ & 0.298 \\
Total & $26(100)$ & $20(100)$ & $6(100)$ & \\
\hline
\end{tabular}

Values are presented as number (\%).

*Traffic accident and suicide.

Wilms tumor, and leukemia) and 2 patients with hepatic fibrosis died from varix bleeding. Another 2 patients died from intractable seizure associated with Kearns-Sayre syndrome and nephronophthisis. Hemorrhages of the lung $(\mathrm{n}=2)$ and the central nervous system (CNS) $(n=2)$ were also significant causes of death. One patient with pulmonary hemorrhage was on $\mathrm{HD}$ and both patients who died from CNS hemorrhages were on HD. Two of the patients died from a traffic accident and suicide. The causes of death of the other 5 patients were unknown. The causes of death between patients on HD and PD were not significantly different (Table 1).

\section{Discussion}

To the best of our knowledge, this is the first report on the outcomes of chronic dialysis in Korean children. The MR of our study population was 19.9 per 1,000 dialysis patient years. This rate is comparable to USRDS data from 2006 reporting an adjusted MR of 56.5 per 1,000 patient years for pediatric dialysis patients (aged 0-19 years, with treatment initiated between 1995 and 1999) $)^{6}$, Dutch data from 2002 reporting an MR of 15.7 per 1,000 patient years ${ }^{7)}$ and Japanese data from 2002 reporting an MR of 15.6 per 1,000 dialysis patient years (in patients aged 0-19 years ${ }^{8}$. Longer-term patient survival data are available from the Australia and New Zealand Dialysis and Transplant (ANZDATA) registry $(n=1,634)$, which has the longest longitudinal follow-up period. The ANZDATA results show a 10-year survival of 79\% and a 20-year survival of 66\% for children under 20 years of age who started RRT between 1963 and 2002 $2^{9}$. Although the length of observation was relatively short in the present study, the 5year overall patient survival (92.1\%) was slightly better than that of ANZDATA (86\%).

Our study found that there was no significant difference of survival between the patients on PD and those on HD $(P=0.908)$. This result corresponds with a report from Taiwanese renal registry which showed no difference of survival between chronic HD and 
PD in patients less than 20 years of age $(P=0.4878)^{10)}$.

Our study also found that younger patients, especially those patients who started dialysis at less than 2 years of age, had poorer survival. The 2011 annual report of NAPRTCS group also reported significantly lower survival rate in children younger than 2 years of age at the beginning of dialysis. Additionally, the ANZDATA registry identified a younger age at the initiation of dialysis as a risk factor for poor survival. The poorer outcome in younger patients can be explained by the higher incidence of life threatening complications of chronic dialysis and more serious comorbidities frequently found in this age group in addition to the shortage of medical equipments and experienced personnel necessary to care them ${ }^{11,12)}$.

The most common cause of death in this study was infection in which dialysis-related sepsis to be most frequent. Wood et al. ${ }^{13)}$ reported that infection was the most common primary cause of death, accounting for 15 of 51 deaths (29.4\%). ESRD is an immunologically compromised condition ${ }^{14)}$, and the accesses for chronic HD or PD make the patients highly vulnerable to infectious complications.

The second most common cause of death in our study was malignancy. All 5 patients who died from the progression of malignancy had obtained their ESRD because of chemotherapeutic agent-induced nephrotoxicity. Comorbidities including malignancies, hepatic fibrosis and CNS diseases lead to death in 9 patients (34.6\%). Shroff et al. ${ }^{15)}$ reported that in a cohort of 98 children on chronic dialysis, 76\% of the mortalities was associated with comorbidities. Additionally, NAPRTCS data have identified comorbidities such as pulmonary hypoplasia and severe developmental delay, oliguria/anuria, and a younger age at the initiation of dialysis as risk factors for increased mortality in infants and young children ${ }^{13)}$.

Just like in adults patients ${ }^{6,16)}$, cardiovascular disease is one of the most significant causes of death in children on chronic dialysis; cardiac arrest is the most commonly reported cause of death in children ${ }^{17)}$. ANZDATA reported that the most common cause of death in children on dialysis was cardiovascular disease (45\%), with the second most common being infection (21\%) $)^{9}$. And the rate of cardiovascular death in pediatric patients with ESRD in USRDS was up to $37 \%{ }^{6}$. In this study, pulmonary hemorrhage, a common manifestation of severe congestive heart failure, was the cause of death in 2 children, but this incidence was lower than those reported elsewhere. Mortality by cardiovascular origin in this study was lower than that of adults or other pediatric studies. The difference could be originated by the fact that pediatric ESRD patients undergo renal transplantation earlier than adults before severe uremic cardiomyopathy develops. In addition, relatively shorter follow-up duration of this study could be another reason. Furthermore, the patients with unknown causes of death might have died from cardiovascular diseases.
It is assumed that the CNS Hemorrhage, which was the cause of death in 2 children on HD, is associated with uncontrolled hypertension or accompanying cerebrovascular diseases.

A limitation of our study is that it is based on the data from the KPCKD registry, which were input by the participating centers, and the registration rate was only $52 \%$. It is speculated that internists who do not participate in the KPCKD registry are treating many adolescent patients with ESRD. Because all patients are eventually transferred to the internist, we, the authors, cannot know the accurate number of the dead patients. Additionally, the followup durations were not long enough to provide data for a longterm survival. To obtain long-term survival data, cooperation with internists is indispensible.

In conclusion, the outcomes of chronic dialysis in Korean children were better than those of adults, and comparable to pediatric studies of other countries as well. To improve the outcomes of children on chronic dialysis, prevention of dialysis-related complications, such as infection or congestive heart failure or CNS hemorrhage due to uncontrolled hypertension, and more aggressive management of treatable comorbidities are necessary.

\section{Conflict of interest}

No potential conflict of interest relevant to this article was reported.

\section{Acknowledgments}

This study was supported by a grant \#30-2010-0040 from the SNUH Research Fund.

\section{References}

1. Warady BA, Chadha V. Chronic kidney disease in children: the global perspective. Pediatr Nephrol 2007;22:1999-2009.

2. van der Heijden BJ, van Dijk PC, Verrier-Jones K, Jager KJ, Briggs JD. Renal replacement therapy in children: data from 12 registries in Europe. Pediatr Nephrol 2004;19:213-21.

3. Chadha V, Warady BA. Epidemiology of pediatric chronic kidney disease. Adv Chronic Kidney Dis 2005;12:343-52.

4. North American Pediatric Renal Trials and Collaborative Studies; 2011 Annual Dialysis Report [Internet]. Boston: NAPRTCS; [cited 2012 Aug 1]. Available from: https://web.emmes.com/study/ped/ annlrept/annualrept2011.pdf

5. ESRD Registry Committee, KSoN; 2010 [Internet]. Seoul: Korean Society of Nephrology; c2006 [cited 2012 Aug 1]. Available from: http://www.ksn.or.kr/journal/2011/index.html.

6. U.S. renal data system. The 2006 Annual data report: Atlas of endstage renal disease in the United States [Internet]. Minneapolis: USRDS Coordinating Center; [cited 2012 Aug 1]. Available from: 
http://www.usrds.org/atlas06.aspx.

7. Groothoff JW, Gruppen MP, Offringa M, Hutten J, Lilien MR, Van De Kar NJ, et al. Mortality and causes of death of end-stage renal disease in children: a Dutch cohort study. Kidney Int 2002;61:6219.

8. Hattori S, Yosioka K, Honda M, Ito H; Japanese Society for Pediatric Nephrology. The 1998 report of the Japanese National Registry data on pediatric end-stage renal disease patients. Pediatr Nephrol 2002; 17:456-61.

9. McDonald SP, Craig JC; Australian and New Zealand Paediatric Nephrology Association. Long-term survival of children with endstage renal disease. N Engl J Med 2004;350:2654-62.

10. Lin HH, Tsai CW, Lin PH, Cheng KF, Wu HD, Wang IK, et al. Survival analysis of pediatric dialysis patients in Taiwan. Nephrology (Carlton) 2012;17:621-7.

11. Lee SE, Han KH, Jung YH, Lee HK, Kang HG, Cheong HI, et al. Peritonitis in children undergoing peritoneal dialysis: 10 years' experience in a single center. J Korean Soc Pediatr Nephrol 2010;14:174-83.
12. Keane WF, Alexander SR, Bailie GR, Boeschoten E, Gokal R, Golper TA, et al. Peritoneal dialysis-related peritonitis treatment recommendations: 1996 update. Perit Dial Int 1996;16:557-73.

13. Wood EG, Hand M, Briscoe DM, Donaldson LA, Yiu V, Harley FL, et al. Risk factors for mortality in infants and young children on dialysis. Am J Kidney Dis 2001;37:573-9.

14. Kato S, Chmielewski M, Honda H, Pecoits-Filho R, Matsuo S, Yuzawa Y, et al. Aspects of immune dysfunction in end-stage renal disease. Clin J Am Soc Nephrol 2008;3:1526-33.

15. Shroff R, Rees L, Trompeter R, Hutchinson C, Ledermann S. Longterm outcome of chronic dialysis in children. Pediatr Nephrol 2006; 21:257-64.

16. Agarwal R, Bunaye Z, Bekele DM, Light RP. Competing risk factor analysis of end-stage renal disease and mortality in chronic kidney disease. Am J Nephrol 2008;28:569-75.

17. Parekh RS, Carroll CE, Wolfe RA, Port FK. Cardiovascular mortality in children and young adults with end-stage kidney disease. J Pediatr 2002;141:191-7. 